\title{
Sustainable Urbanisation and Community Well-Being in Suburban Neighbourhoods in Beijing, China
}

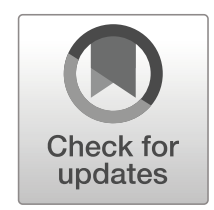

Miao Qiao $^{1} \cdot$ Cecilia Wong $^{1} \cdot$ Wei Zheng $^{1}$

Received: 13 November 2018 / Accepted: 20 February 2019 /Published online: 22 March 2019

(C) The Author(s) 2019

\begin{abstract}
Rapid outward expansion of urban land in many of China's cities has resulted in the production of spatially diverse suburban areas, including newly developed residential complexes and the incorporation of existing neighbourhoods into the urban fabric. The concept of 'community well-being' provides a useful framework to examine the relationship between the well-being of individuals and the physical environment and spatial conditions in which they live. While the study of subjective well-being and its determinants has been rapidly established in China, most research tends to be at the city and provincial level. By adopting a spatial planning perspective, this paper aims to make an original contribution by examining community well-being in Beijing's suburban neighbourhoods, which formed via the rapid suburbanisation process underway since the 1990s. The underlying dynamics and spatial variations of community well-being are assessed by subjective and objective measures and taking both personal attributes and neighbourhood environmental factors into account to draw out policy implications for sustainable urban development.
\end{abstract}

Keywords Community well-being · Sustainable development · Urbanisation · Suburban neighbourhoods · Beijing

Cecilia Wong

cecilia.wong@manchester.ac.uk

Miao Qiao

qiaomiaojoe@163.com

Wei Zheng

helen.zheng@manchester.ac.uk

1 Department of Planning and Environmental Management, Manchester Urban Institute, The University of Manchester, M13 9PL, Manchester, UK 


\section{Introduction}

Urbanisation in China has been growing at an unprecedented pace and scale, with nearly $60 \%$ of the population urbanised by 2020 and over 1 billion urbanites anticipated by 2030 (UNDP 2013). In the past three decades, rapid outward expansion of urban land in many cities of China has resulted in the production of spatially diverse periurban areas, including newly developed residential complexes and the incorporation of existing neighbourhoods into the urban fabric (Cheng et al. 2017). The peri-urban area is seen as a flexible and transitional space that is fluid to accommodate migration and heterogeneous production and consumption functions (Rauws and de Roo 2011). Since the mosaics of activities in peri-urban areas are highly dynamic, their composition, interaction and configuration not only create opportunities but also result in major challenges in terms of infrastructure development, provision of public amenities, environmental degradation, land use conflicts and social inequalities (Allen 2003; Sun et al. 2011). Unlike the urbanisation process in the West that took place during industrialisation in the 19th and early 20th centuries, urban expansion in China is happening within three decades and can be characterised as rampant and diverse. This means that neighbourhoods that have emerged in transient peri-urban locations will rapidly become suburbs in the outer metropolitan area when the continuous sprawling force has driven the peri-urban frontiers further outwards.

The publication of China's 'National New Urbanisation Plan' (NUP) in 2014 (State Council 2014) signifies the recentralisation of state power to overhaul its urban development strategy ( $\mathrm{Wu}$ 2016). The NUP is an ambitious economic stimulation strategy that moves away from export-led manufacturing to domestic consumption, addressing urban-rural inequalities and promoting environmental sustainability (Chang et al. 2016). The policy visions in the NUP are delivered through the imperative of 'ecological civilisation'1 to reshape urban growth towards a more human-centred and environmentally sustainable pathway (Wong et al. 2018). Since the NUP is a sustainable urbanisation strategy to achieve China's development goal of a 'moderately welloff and comfortable society' (xiaokang shehui), with a broader socio-cultural notion beyond economic advancement, the 'well-being' outcomes of urbanisation in suburban neighbourhoods developed in the former peri-urban locations are thus pivotal to future planning and management of urban growth.

The concept of 'community well-being' (CWB) provides a useful framework to examine the relationship between the well-being of individuals and the physical environment and spatial conditions in which they live (Lee et al. 2015). CWB also serves a normative function of empowering residents to act upon their immediate living space and bring about changes for better outcomes for the neighbourhood (Hothi et al. 2008; Lee et al. 2015). While the study of subjective well-being and its determinants has been rapidly established in China (see Davy and Rato 2012), most tend to focus on the city and provincial level (e.g. Huang and Xing 2005; Smyth et al. 2010). It was not until recently that a few studies explicitly examined the linkage between personal wellbeing and residential environment at finer spatial scales (e.g. Dang et al. 2017; Liu et al.

\footnotetext{
1 'Ecological civilisation' is a term adopted by China as an alternative to the Western view of sustainable development. The term 'civilisation' signifies a paradigm shift of global human values and concerns over environmental issues (see Savage and Feng 2018).
} 
2017; Ma et al. 2018). The unit of analysis of these studies nonetheless very much focused on individuals, rather than the neighbourhoods to which they belonged, and the survey samples were drawn from the urban core, rather than the most expanded and pressurised outer metropolitan areas.

Different well-being issues step to the fore at different spatial scales (Hamiduddin 2015). From a planning perspective, a neighbourhood is a spatial unit that builds the physical and social fabric of a city (Talen and Shah 2007) and is crucial to residents' quality of life as they live and spend most of their time there (Rohe 2009). This paper, from a spatial planning perspective, aims to make an original contribution by examining CWB in Beijing's suburban neighbourhoods that formed via the rapid suburbanisation process underway since the 1990s. The underlying dynamics and spatial variations of CWB in 15 suburban neighbourhoods are assessed by subjective and objective measures by taking both personal attributes and neighbourhood environmental factors into account to shed light on the debate of sustainable urban development and planning. The next two sections first provide a critical review of literature on the relationship between urbanisation, sustainable development and CWB; this is followed by a discussion on spatial restructuring in Beijing and how it shapes the development of different types of suburban neighbourhoods, setting the scene of this study. The research methodology section explains the conceptual framework, key hypotheses, data collection and analytical methods. The fifth section presents the empirical findings of hypothesis testing. A discussion of the research findings and their planning policy implications is provided in the penultimate section before the conclusion is drawn.

\section{Urbanisation, Sustainable Development and CWB}

As affirmed in Habitat III's New Urban Agenda, the international policy community has turned to cities as the driver to end poverty, develop sustainable and inclusive urban economies, and deliver environmental sustainability (UN-Habitat 2016). However, there have been debates over the paradoxical relationship between urbanisation and sustainable development. AtKisson (2006) made a provocative assertion that industrial and technological growth is destroying much of nature due to the intricacy of balancing nature and humanity. A positive relationship between economic growth and $\mathrm{CO}_{2}$ emissions was indeed found in China's urban areas (O'Neill et al. 2012; Liu et al. 2012). Others were more optimistic and saw the sustainability discourse opening up possibilities for transformative change (Beauregard 2006). With the economies of scale brought by the concentration of population and activities, cities are seen as important in developing multi-purpose solutions for the more efficient use of resources and planning for sustainable urban forms (Bettencourt and West 2010; Francesch-Huidobro 2016). Given the unstoppable pace of global urbanisation and that an ideal type of sustainable cities does not exist (Holden et al. 2008), it is crucial to envisage urban sustainability as a goal and to improve human well-being at the same time.

In order to track progress on sustainable development, different concepts, indicators and tools have been proposed. The use of gross domestic product (GDP) as an indicator of development has long been criticised for its narrow economic focus and neglect of subjective assessment and territorial context (e.g. Miles 1985; Sawiciki and Flynn 
1996). UN-Habitat (2012) thus argues for a broader conception of human and societal well-being in the development of its Cities Prosperity Index (Wong 2015). The concept of happiness is also put forward by the World Bank as a subjective, relative and holistic measure of human progress (Helliwell et al. 2016). Scholars from different disciplines have been advancing ideas and methods to conceptualise and measure the well-being of individuals, communities, cities and countries (e.g. Diener 2006; Phillips and Wong 2017). However, these diverse research efforts have not been consistently integrated into a comprehensive and evidence-based theoretical framework (Liu et al. 2017). Subjective well-being has been largely researched from the hedonic perspective, with a distinction between a cognitive and an affective component and with life satisfaction and happiness commonly adopted as their respective proxy measures (Diener et al. 1999; Nieboer et al. 2005; Ryan and Deci 2001). The measure of well-being often includes subjective variables such as self-reported feelings and assessments as well as objective measures of tangible personal attributes and environmental factors (Cummins 2018; Hothi et al. 2008).

Research on well-being has extended from the personal to the community level to conceptualise well-being as a collective construct (Foo et al. 2015). The focus of community carries a collective and geographical connotation that is often associated with clusters of residences and certain spatial attributes, which is more akin to the concept of neighbourhood (Galster 2001). CWB is embedded with multidimensional values including economic, social, environmental, cultural, psychological and political aspects that impact on individuals and their communities to fulfil their needs and desires (Lee et al. 2015; Sung and Phillips 2016; Wiseman and Brasher 2008). While each of these values has a vital role in shaping community development and perceptions, they can combine in many different ways depending on the scale, context and particular characteristics of the community. For example, the type of governance structure, the physical environment, and certainly needs and desires of a community's residents can impact on well-being (Phillips and Wong 2017). The holistic nature of CWB means that it is subject to different interpretations and being used interchangeability or jointly with other related yet different concepts such as happiness, quality of life, community development and sustainable development (see Kee 2017). Due to the conceptual ambiguity problem, the understanding of CWB requires drawing on robust empirical evidence. When assessing community conditions, living environment and neighbourhood space were often treated as a 'container' where physical, social, institutional and environmental factors can be identified and measured in an enclosed system (Cuthill 2002). This, however, neglects the multiple dynamic relations and meanings embedded in the spatial contexts where the community is situated and interacts with. Geographers and planners have thus argued for the importance of examining the effects of spatial contexts on CWB; which can engender discourses on governance and collective wellbeing that have direct implications for policy-making (Schwanen and Atkinson 2015).

Social scientists have recently called for a greater emphasis on acknowledging the presence of cultural differences, as well as the ability to use and accommodate differences in a productive manner to achieve urban sustainability (Roy 2009; Watson 2016). Differences in cross-cultural context and languages were found presenting major challenges to develop a robust comparative study of subjective well-being (Cummins 2018). Indeed, about $10 \%$ of subjective well-being studies in China adopted 
a scaling methodology specifically tailored for their own study objectives, samples and contexts (see Chen and Davey 2008). In Davy and Rato (2012) critical review of wellbeing research in China, they highlighted the paradoxical findings between objective and subjective well-being. Despite living in adversarial socio-economic conditions, farmers in rural areas (e.g. Davey et al. 2009) and rural-urban migrant workers (e.g. Nielsen et al. 2010) were found having positive life satisfaction. These groups' contentment with life could be related to the socio-temporal comparison with their previous living conditions which had been significantly improved. Davy and Rato (2012) also point out that Chinese respondents are more likely to choose moderate scores in psychometric scales, as documented in social science literature. Cultural differences come into play in the perception of 'satisfaction' and 'happiness', as Chinese respondents do not always differentiate the two terms clearly when referring to well-being (Lau et al. 2005).

Recently, a few studies have adopted a spatial perspective to examine the relationships between well-being, residential satisfaction, and residential environments in China. Dang et al. (2017) show that neighbourhood type (based on housing classification) was significantly correlated with subjective well-being, with residents in commercial housing neighbourhoods reporting higher levels of subjective well-being than those in work-unit and affordable housing neighbourhoods. By mapping environmental satisfaction at the sub-district level of Beijing's urban core, Ma et al. (2018) found that subjective neighbourhood evaluation had greater influences on life satisfaction than the objective residential environment. In another study of older adults in Shanghai, Liu et al. (2017) confirm that elements of the residential environment such as good accessibility and quality housing bore a stronger impact on subjective well-being than individual resources. Dong and Qin's study (2017) reports that the neighbourhood environment showed a significant but minor effect on residents' subjective well-being.

While a new wave of well-being studies begins to incorporate residential environments and spatial contexts into their research design, their robustness has often been constrained by sample size and design. The spatial unit of analysis is either too crude to be a meaningfully defined neighbourhood ${ }^{2}$ or the number of observations ${ }^{3}$ is too small to perform more robust analysis. These studies tend to examine core urban areas rather than the rapidly expanding outer metropolitan areas and focus on overall environmental satisfaction without breaking it down into different components (e.g. sport facilities, green space and transport accessibility). This study aims to further the debate by examining CWB in suburban neighbourhoods from a spatial planning perspective to shed light on the importance of integrating CWB into the delivery of a new type of urbanisation in China. With this specific focus, CWB will be understood as communities of place situated within geographic spaces (after Phillips and Wong 2017), and the variable observed will not only focus on residents' personal well-being, but also include different aspects of the neighbourhood environment to inform planning for sustainable urbanisation.

\footnotetext{
$\overline{2}$ Sub-districts of urban Beijing were adopted in the study by Ma et al. (2018). These are rather large units with an average population of 90,000 and an area of $10 \mathrm{~km}^{2}$ showing very diverse spatial forms and characteristics.

${ }^{3}$ Dang et al. (2017) utilise broad neighbourhood categories to perform multi-level analysis, with 2606 valid questionnaires. Since 354 neighbourhoods in urban Beijing were involved, the average number of questionnaires for each neighbourhood was only 7.5.
} 


\section{Spatial Restructuring and Suburban Neighbourhoods in Beijing}

Spatial restructuring of the Beijing Metropolitan Region (BMR) has undergone a series of market-oriented reforms since the 1980s, inextricably intertwined with government interventions at central and local levels, to create complex webs of spatial relationships. BMR has a single central area and a zonal structure of five concentric ring roads linked by radial expressways. Its builtup area has expanded by 4.5 times from 310 to $1401 \mathrm{~km}^{2}$ and its population rose from 9.2 to 21.7 million between 1981 and 2015. When Beijing was designed as the national capital, it was a rather compact city featuring the 'work unit' (danwei) system with planned co-location of workplace and residence (Wang and Chai 2009). Following housing and land market reforms, the work-unit system eventually faded out. A key running thread of Beijing's urbanisation is the strategic investment on transport infrastructure to connect the designated 'decentralisation sites'. Beijing's fourth and fifth ring roads were built to connect the ten 'dispersed clusters' planned in the 1991 Beijing Master Plan and four new metro lines were opened to connect the new towns planned in the 2004 Beijing Master Plan. With the concentration of employment opportunities in the urban centre and the sprawling of residential development outwards, the uneven improvement of transport infrastructure has resulted in complex commuting patterns with varying journey distances and times from different neighbourhoods (Zhao et al. 2011).

The geographical space of Beijing's suburban area is dynamic and not that clearly defined. Many studies have therefore adopted the spatial categorisation set out in Beijing's 11th Five-Year-Plan (2005-2010). The 18 districts are grouped into 4 zones: the urban core function zone (Xicheng and Dongcheng); urban function extension zone (Haidian, Chaoyang, Fengtai and Shijingshan); urban development new zone (Tongzhou, Shunyi, Changping, Fangshan and Daxing); and ecological conservation zone (Mengtougou, Huairong, Pinggu, Miyun and Yanqing). In the Beijing Master Plan (2004-2020), the urban function extension zone was recognised as the 'inner suburban area', and the urban development new zone as the 'outer suburban area'. Because of the rapid pace of urbanisation, what was once deemed as the 'inner suburban area' has already been largely incorporated into the central urban districts, as documented in the latest Beijing Master Plan (2016-2035).

In this paper, Beijing's suburban area can be practically defined as the five districts in the urban development new zone and parts of Haidian and Chaoyang that extend to the sixth ring road. Therefore, suburban is now a more accurate description of those peri-urban neighbourhoods built around the 1990s and early 2000s. The socio-economic composition of these neighbourhoods is very diverse, ranging from makeshift migrant enclaves, through to middle-class residential complexes, and high-end gated communities (Zhao et al. 2011). Based on their urban development process, housing characteristics and relevant policy contexts, five key suburban neighbourhood types are identified from the 15 selected neighbourhoods in this study: economic and comfortable housing; suburban public housing; new village housing; small property housing; and the urban village (see Table 1). 
Table 1 Development process and characteristics of suburban Beijing neighbourhoods

Economic and comfortable housing: developed from the 1990s onwards

Economic and comfortable housing (Jingiishiyongfang) or affordable housing is essentially commercial housing built on free (or at a low price) land allocated by local government in peripheral locations (normally with a less favourable environment) to boost the supply of the low-end market. Under government price control, affordable housing is much cheaper than market housing, but their resale is restricted within a certain time limit. With profit capped at 3\%, developers are reluctant to engage in such development. Nonetheless, they are under pressure to do so to gain an advantage over future land bidding projects. Under the current system, affordable housing will continue to be driven to peripheral locations, with poor construction quality and inadequate infrastructure and public services. As there is no robust eligibility check of a buyer's household income (under 60,000 RMB) and other requirements (e.g. Beijing household registration $(h u k o u)$ ), affordable housing is often bought by those moderately well-off rather than the targeted 'low- to middle-income group'.

\section{Suburban public housing: developed in the late 1980s and 1990s}

In order to provide housing for public organisation employees (e.g. civil servants and school teachers) in suburban counties, a semi-market solution was devised. Local government granted a piece of land, or sold it at a low price, to developers of housing developments specifically for state-owned enterprises or other public organisations (danwei). Upon completion, danwei made bulk purchases of these housing units and let them to their employees; the housing was subsequently sold to sitting residents during housing reforms in the late 1990s. Since house sales were guaranteed, the developer was not incentivised to strive for better building and design quality. This has led to the deterioration in the physical structure of buildings and other neighbourhood facilities. With danwei increasingly withdrawing from housing provision and maintenance duties, the provision of community services has also been commodified. Many of the original owners have moved out, which has dampened the sense of community.

\section{New village housing: formed in the early $2000 \mathrm{~s}$}

Since 1998, danwei had gradually retreated from housing provision. New village housing is very much a product of the formal urbanisation process through major infrastructure construction and rural land appropriation. Apart from commodification of danwei housing, commercial housing development is used to finance urban development projects. Consequently, new villages turn out to be much larger residential settlements than the previous rural villages. These neighbourhoods are developed by real estate developers and manged by property management companies. Such housing development schemes are incidental; it is difficult to achieve economies of scale to provide high quality public services to these sporadically located neighbourhoods. This type of housing development has exerted an extra burden on public service provisions in peri-urban locations. Nonetheless, it remains attractive to consumers because the price is affordable.

\section{Small property housing: developed since the early 2000s}

Small property housing has ambivalent property rights as the housing unit is developed on rural 'collective' land without going through the legally approved process. The housing market boom in Beijing has driven up the land value. Since rural villages are located in a more attractive natural environment, there are strong incentives for local villagers to profit from housing developments on collective land. Since such development is informal, the amount of investment made is rather limited. The village collectives tend to hire local builders to carry out the construction with very basic building quality and design. Without a municipal utility supply, small property housing has to rely on alternative solutions for water, electricity and waste treatment.

\section{The urban village: since $1990 \mathrm{~s}$}

The urban village (chengzhongcun) or village-in-the-city is formed when urban expansions besiege rural villages without integrating them into formal urban development. Since rural land is collectively owned, indigenous villagers can only build informal housing on collectively owned land for leasing (Wu et al. 2013). Informal housing in urban villages has become the main source of low-cost housing supply for migrant workers. With the introduction of government-led redevelopment programmes of urban villages, many indigenous villagers have been relocated and compensated; in contrast, migrant workers as tenants have no rights and thus have been forced out, receiving no compensation (Wong et al. 2018). Urbanisation and the redevelopment of urban villages have pushed migrants further and further outwards to urban peripheries. 


\section{Research Methodology}

This study focuses on understanding CWB in neighbourhoods in the former transient peri-urban areas of Beijing from a spatial planning perspective. As explained earlier, the conception of CWB here will be about communities of place and will examine both residents' personal well-being as well as neighbourhood environment with subjective and objective measures to inform planning for sustainable urbanisation. The relationships between the subjective personal well-being of residents, their personal attributes (as a proxy objective measure of personal well-being) and satisfaction with (subjective measure), and assessment (objective measure) of, neighbourhood environmental conditions are conceptualised in Fig. 1. The variations of these relationships in the five identified neighbourhood types are also examined to establish the impact brought about by different urbanisation experiences of CWB.

\section{Survey and Sampling Methodology}

A large-scale survey was carried out in BMR between May and June 2017 and a structured questionnaire was used to collect data on personal information, satisfaction with neighbourhood environment and waste management, satisfaction with quality of life, and perceived level of happiness. The participants were chosen on the basis of a multi-stage, spatial cluster sampling approach. A spatial typology of BMR into three area groups (inner metropolitan, outer metropolitan and peri-urban) was first created by classifying land use form, demographic variables, and transport accessibility at the township-level administrative unit (Wong et al. 2018). After consulting with experts on spatial development in Beijing, five townships were then chosen from the outer metropolitan group for this study, which were further validated with the spatial expansion patterns of Beijing to confirm that they are situated in those areas rapidly urbanising between 1990 and 2015 (see Figs. 2a, b).

Based on the targeted sample size of $0.2 \%$ of the total residential population of the five townships (i.e. 1680 out of 840,240) and a built-in attrition rate of $15 \%$, about 1930 survey participants were targeted. The sampling frame of neighbourhoods was based on the National Statistics Bureau's 2014 sample of neighbourhoods in Beijing townships.

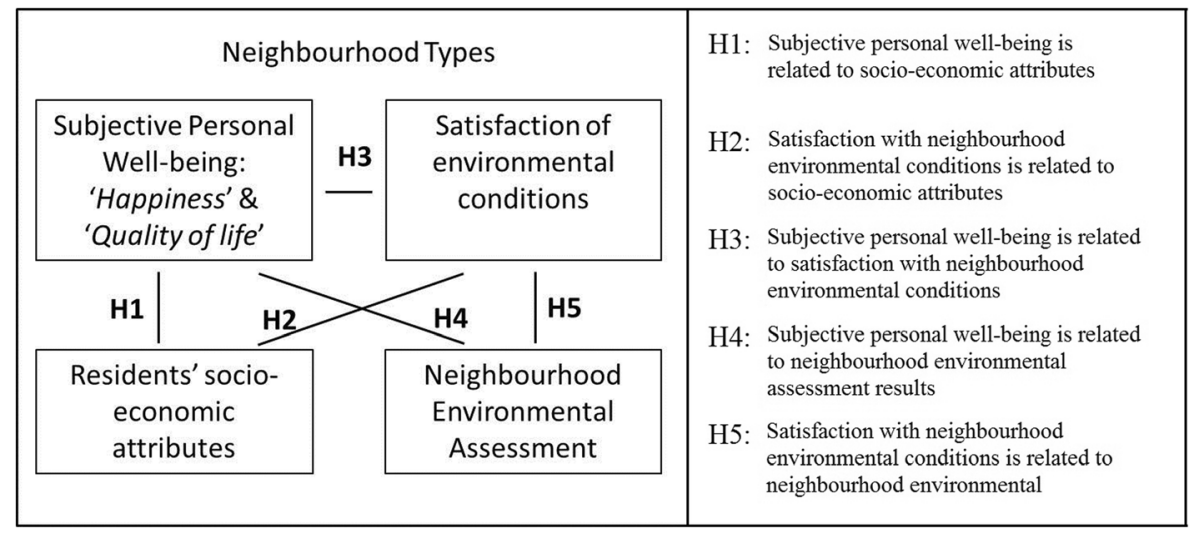

Fig. 1 Conceptualising CWB at the neighbourhood level 


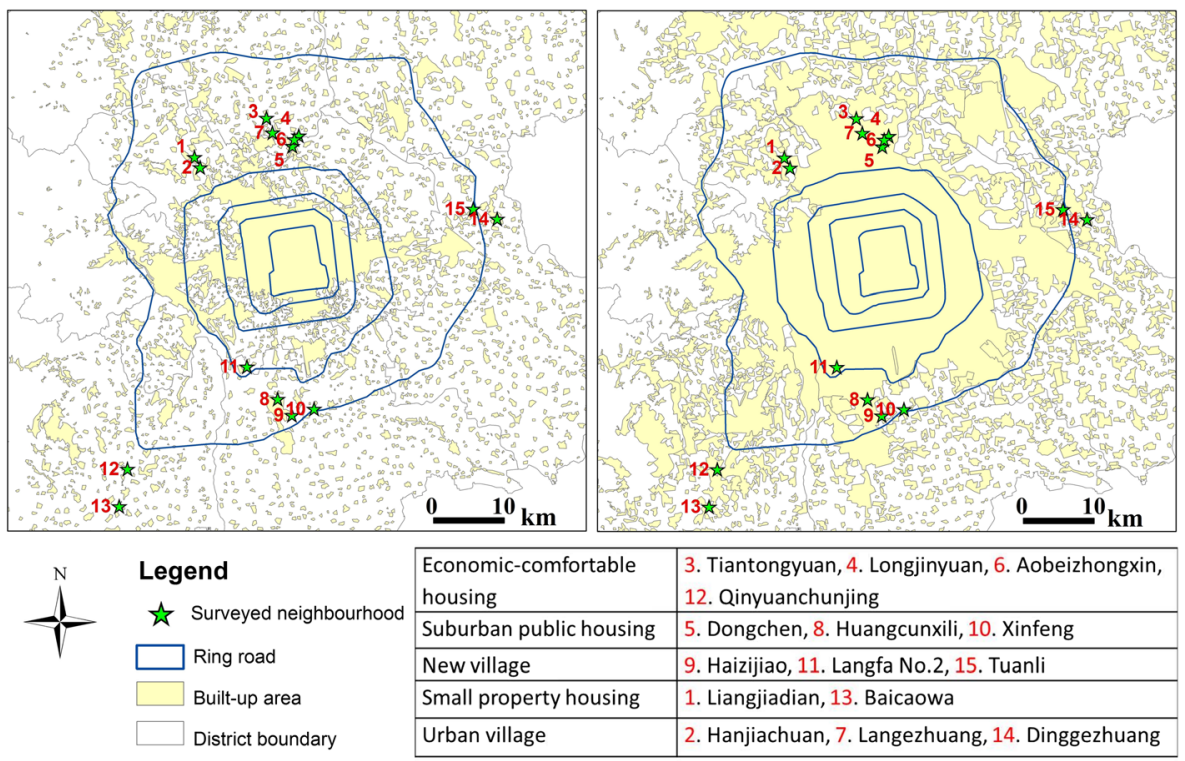

Fig. 2 Surveyed neighbourhoods and urban built-up areas in: (a) 1990 and (b) 2015

Altogether, 15 neighbourhoods were identified from the 5 townships and around 120 participants were approached in each neighbourhood with a non-probability quota sample based on age and gender distribution at the township level. In total, 1812 questionnaire responses ${ }^{4}$ were collected, which is deemed to be a large-scale community survey when compared with similar studies in Beijing (e.g. Zhao et al. 2011; Zhao 2012). Here, a neighbourhood indicates a housing estate (xiaoqu) or a village (cun), the boundaries of which are officially defined in planning and land use documents. The study focuses on studying both the immediate and wider environmental conditions of the neighbourhood. The immediate neighbourhood refers to areas within the neighbourhood boundaries and the wider neighbourhood refers to areas that are easily accessible on foot or by bicycle within a range of $1 \mathrm{~km}$.

\section{Key Variables and Statistical Testing}

The subjective well-being of residents was ascertained by measuring life satisfaction and happiness through the questions of 'How satisfied are you with your quality of life?' and 'How happy are you with your life?' on a 5-point Likert scale ('1: very dissatisfied/unhappy'; '2: dissatisfied/unhappy'; '3: neutral'; '4: satisfied/happy'; and '5: very satisfied/happy'). In terms of personal attributes, data on respondents' demographic and socio-economic characteristics were collected: age, education level, occupation, home ownership, living space, car ownership, household income level and

\footnotetext{
${ }^{4}$ Besides age and gender, participants were asked a filter question of whether they had any physical and mental health conditions that might affect their participation in the survey. With many neighbourhoods gated in Beijing, it was not possible to gain direct access to many building blocks. The participants were approached in the public space of the neighbourhood and the survey excluded potential participants who were not healthy adults to meet with the university's ethical approval requirements.
} 
length of residency in the neighbourhood. These variables were summarised for hypothesis testing via latent class analysis, which will be explained later.

With regard to the neighbourhood's environmental conditions, residents were asked about their level of satisfaction with different aspects of the living environment within and surrounding the neighbourhood. Question items included: sports facilities, air quality, tranquillity, walkability, access to nature, parks and playgrounds, green space, infrastructure, public services, and rubbish and used item recycling. A 5-point Likert scale was used in the responses. The research team also carried out a criterion-based assessment of the quality of living environment in each neighbourhood. The assessment criteria, regarding the cleanliness, aesthetics, green infrastructure density, and park management of the neighbourhood, were based on both local contexts and relevant literature (e.g. van Kamp et al. 2003; Dunstan et al. 2005; Fleury-Bahi et al. 2013). The assessment results were recorded with photographs and text commentaries, which were then converted into a scoring system. In addition, residents' accessibility to metro, bus, and shopping mall was measured via GIS analysis with Baidu Map. Principal component analysis was performed to develop composite indices of these question items (see explanation below).

Different statistical methods were applied to test the hypotheses. Kruskal-Wallis tests and Chi-square tests were used to test how socio-economic groups and neighbourhood types differ in residents' subjective well-being and their level of satisfaction with different environmental conditions. Given the characteristics of different variables and the assumptions of statistical tests, Spearman's correlations were applied to test the relationship between residents' subjective well-being, their level of satisfaction regarding different environmental conditions, and the environmental assessment outcomes of the neighbourhood.

\section{Latent Class Analysis}

Latent class analysis (LCA) was performed with Mplus on variables measuring residents' socio-economic characteristics to classify them into mutually exclusive groupings for hypothesis testing. LCA is a multivariate analysis that induces the latent relationships among observed variables rather than just seeking similarities (Hagenaars and McCutcheon 2002) and has been widely applied to delineate meaningful groupings of individuals (Liu et al. 2018). Based on seven variables of residents' demographic and socio-economic characteristics, three socio-economic groups were identified by the LCA model (see Fig. 3). ${ }^{5}$

Table 2 provides a pen-picture of the three socio-economic groups: Urban Adversity, Twilight Community, and Suburban Comfort. The composition of the three socioeconomic groups also varies across the five neighbourhood types. As expected, most residents in urban villages belong to the Urban Adversity group, comprise of people who rent cheap housing there. The Twilight Community constitutes the major group in new village and small property housing neighbourhoods. Both the Twilight Community and the Suburban Comfort groups have a major presence in suburban public

\footnotetext{
${ }^{5}$ Methods such as Akaike's information criterion, Bayesian information criterion, log-likelihood, entropy and a corrected LR test were used to identify the most robust model. The distribution of sample size in each class and the interpretability of the model were also considered.
} 


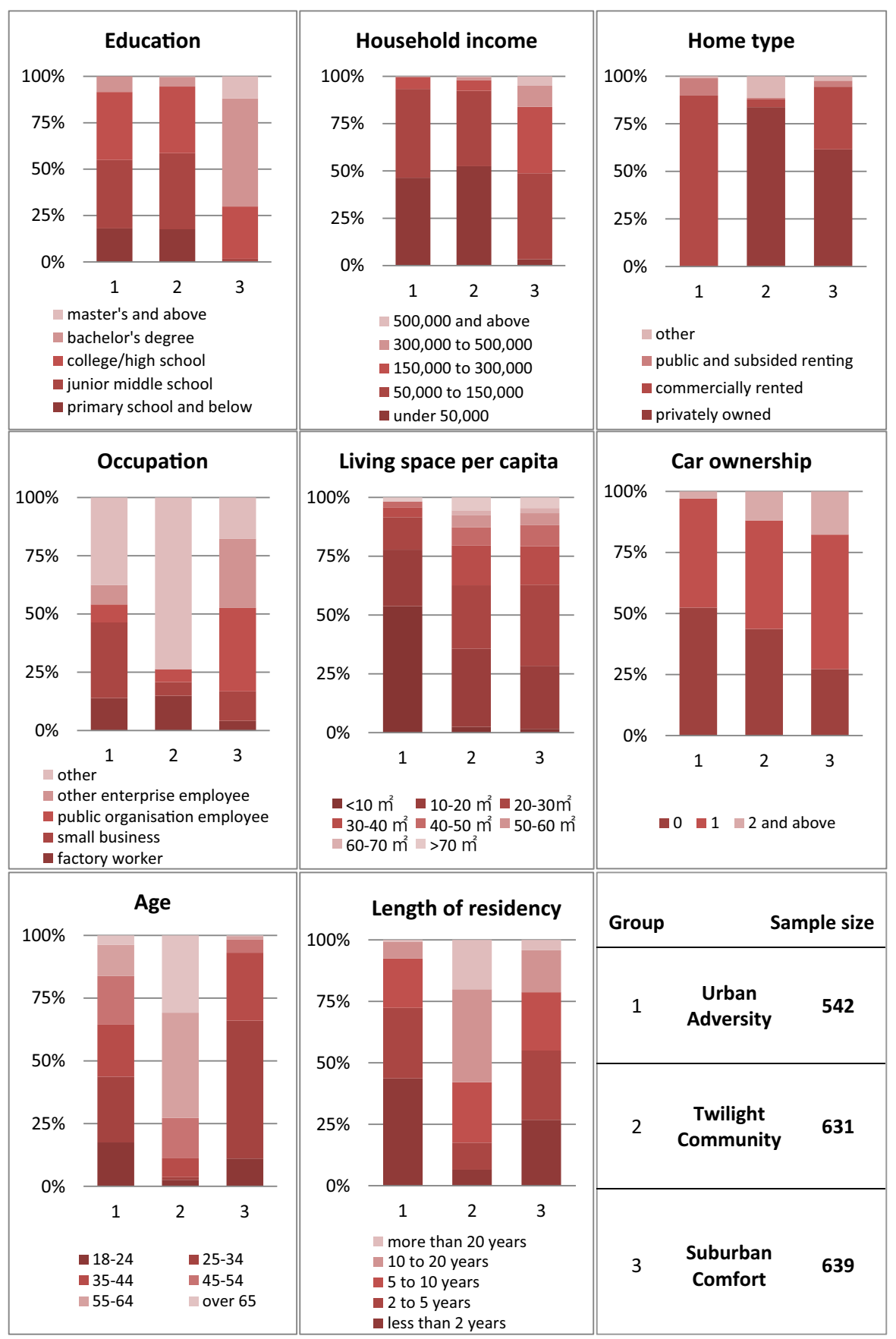

Fig. 3 Socio-economic characteristics of the three socio-economic groups by LCA

housing neighbourhoods. Over half of those living in economic and comfortable housing neighbourhoods are from the Suburban Comfort group. 
Table 2 Descriptions of the three socio-economic groups

Urban Adversity: This group represents the least affluent and less educated residents who work in small businesses and are recent tenants in the neighbourhood. Around half of residents in this group have an annual household income below 50,000 RMB and nearly $60 \%$ only have education up to junior middle school level. Most of them live in commercially rented housing and over half of the residents have living space of less than $10 \mathrm{~m}^{2}$ per head. Residents are from different age groups but $70 \%$ of them have lived in the neighbourhoods for less than 5 years. They are mainly engaged in small businesses, farming or unemployed. It is interesting to note that about $45 \%$ of them own a car, as they may rely on the car to do business and to commute.

Twilight Community: This group is characterised by the more established residents in the neighbourhood, with over $70 \%$ aged 55 and above; about $60 \%$ have lived in the neighbourhood for over 10 years. Despite the fact that their education level and household income level are rather similar to those in the Urban Adversity group, $84 \%$ of them are home owners and $56 \%$ own at least one car. They also enjoy better living space as over $60 \%$ of residents have over $20 \mathrm{~m}^{2}$ per head. This group consists of many retired residents and farmers.

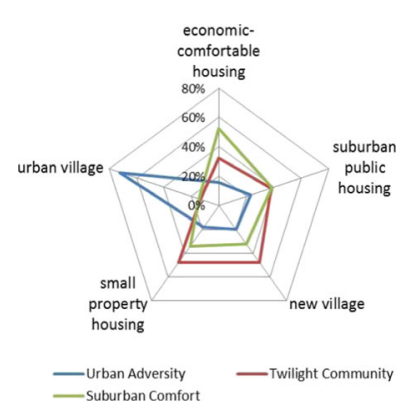

Suburban Comfort: This is by far the most affluent and educated group, but also with a very young demographic profile ( $93 \%$ aged under 45 ). Over half of residents in this group have an annual household income above Beijing's average level of $150,000 \mathrm{RMB}$ and nearly a fifth earned over 300,000 RMB per annum. This is probably related to the fact that over $70 \%$ of them are university graduates and two-thirds work in public organisations or private enterprises. About $60 \%$ are home owners and over $80 \%$ have at least one car. They have very comfortable living space, as over $70 \%$ have more than $20 \mathrm{~m}^{2}$ per head and many moved to the neighbourhood between 2 and 20 years ago.

\section{Principal Component Analysis}

In order to summarise the value of two sets of variables measuring satisfaction with neighbourhood environmental conditions and the neighbourhood environmental assessment, as well as constructing meaningful indices for hypothesis testing, Principal Component Analysis (PCA) was conducted with SPSS to extract factors that are highly correlated with the variables. PCA is a multi-variate statistical technique for extracting summary variables that account for most of the variance from a set of possibly correlated variables (Jolliffe 2011). The transformation procedures of PCA involve examination of the correlation between variables, elimination of variables that contribute relatively little information, and determination of the weighting of variables for indices (Harris et al. 2011).

Three main components, explaining the satisfaction level with different environmental conditions, were extracted and together they explained $62 \%$ of the variance: (ES1) satisfaction with the wider neighbourhood environment; (ES2) waste management in the neighbourhoods; and (ES3) satisfaction with the immediate neighbourhood environment (see Table 3). ES1 has the strongest influence of the three factors as it accounts for $44.6 \%$ of the variance alone, whereas ES2 and ES3 explain $9.1 \%$ and $8.4 \%$ respectively. It is interesting to note that satisfaction with sports facilities in the immediate neighbourhood was found to be statistically linked to satisfaction with the wider environment in ES1. For an environmental assessment of the neighbourhood, three main components were also identified and they explain $83 \%$ of the variance: (EA1) immediate neighbourhood environmental assessment; (EA2) outer neighbourhood environment; and (EA3) accessibility to transport and facilities (see Table 4). The variance explained by the three components is more evenly distributed, with EA1 accounting for 36.7\%, EA2 28.3\% and EA3 18.2\%. 
Table 3 Factor loadings for satisfaction level with different environmental conditions

\begin{tabular}{llll}
\hline & ES1 & ES2 & ES3 \\
\hline Immediate neighbourhood satisfaction: & & & \\
sport facilities & $\mathbf{0 . 5 8 3}$ & 0.318 & 0.530 \\
air quality & 0.367 & 0.293 & $\mathbf{0 . 7 6 9}$ \\
tranquillity & 0.339 & 0.193 & $\mathbf{0 . 8 0 8}$ \\
walkability & 0.481 & 0.276 & $\mathbf{0 . 7 9 5}$ \\
Overall living environment & 0.589 & 0.347 & $\mathbf{0 . 8 1 4}$ \\
Wider neighbourhood satisfaction with: & & & \\
access to nature & $\mathbf{0 . 6 2 8}$ & 0.280 & 0.579 \\
parks and playgrounds & $\mathbf{0 . 7 5 5}$ & 0.292 & 0.521 \\
green space & $\mathbf{0 . 7 0 3}$ & 0.309 & 0.647 \\
nearby sport facilities & $\mathbf{0 . 7 3 3}$ & 0.297 & 0.486 \\
infrastructure & $\mathbf{0 . 7 4 1}$ & 0.209 & 0.285 \\
public services & $\mathbf{0 . 7 7 5}$ & 0.288 & 0.245 \\
overall environmental quality & $\mathbf{0 . 7 9 5}$ & 0.353 & 0.589 \\
Satisfaction with rubbish recycling & 0.276 & $\mathbf{0 . 8 7 4}$ & 0.250 \\
Satisfaction with used item recycling & 0.277 & $\mathbf{0 . 8 7 7}$ & 0.229 \\
Eigenvalue & 6.240 & 12.76 & 1.174 \\
Percentage of variance explained & 44.569 & 9.111 & 8.385 \\
\hline
\end{tabular}

The bold emphasises the largest loading of each variable for the main components (ES1/ES2/ES3); the italic presents relevant statistical results when conducting PCA.

The factor loadings of PCA were then used to calculate six sub-indices and two overall indices with the following formula. The variance explained by each component was used as the value for $W_{j}$ and the loadings of variables were used as value for $L_{i}$. Since the variables of environment assessment have different scales, standardisation procedures were performed before calculating the overall score for each sub-index.

Table 4 Factor loadings of neighbourhood environmental assessment

\begin{tabular}{llll}
\hline & EA1 & EA2 & EA3 \\
\hline Cleanliness & $\mathbf{0 . 9 5 1}$ & -0.027 & -0.131 \\
Aesthetics & $\mathbf{0 . 9 1 9}$ & 0.164 & -0.140 \\
Green density in the neighbourhood & $\mathbf{0 . 8 1 6}$ & -0.140 & -0.238 \\
Green density outside the neighbourhood & 0.351 & $\mathbf{0 . 7 4 5}$ & 0.272 \\
Park management & -0.111 & $\mathbf{0 . 9 2 9}$ & -0.293 \\
Culture and aesthetics of parks & -0.131 & $\mathbf{0 . 9 0 8}$ & -0.327 \\
Accessibility to metro stations & 0.150 & 0.378 & $\mathbf{- 0 . 8 7 6}$ \\
Accessibility to bus stops & 0.521 & 0.041 & $\mathbf{- 0 . 7 4 7}$ \\
Accessibility to shopping malls & 0.112 & 0.083 & $\mathbf{- 0 . 8 6 0}$ \\
Eigenvalue & 3.300 & 2.544 & 1.645 \\
Percentage of variance explained & 36.667 & 28.263 & 18.275 \\
\hline
\end{tabular}




$$
F_{j}=\sum_{i=1}^{m}\left(V_{i} L_{i}\right)
$$

Where $F_{j}$ denotes the grouped factor based on factor analysis on different variables, $V_{i}$ is variable $i, \mathrm{~L}_{\mathrm{i}}$ represents the weight of variable $i$ contributing to factor $j$, and $m$ is the number of variables grouped to factor $j$.

$$
S=\sum_{j=1}^{n}\left(F_{j} W_{j}\right)
$$

In which $S$ denotes the overall score, $W_{j}$ is the weight of factor $j$ to the overall score, and $n$ is the number of factors for the overall score of the overall index.

\section{Understanding CWB in Beijing's Suburban Neighbourhoods}

The relationship between the two measures of subjective personal well-being, the affective element of happiness and the cognitive element of quality of life, is found to be moderately correlated $(\mathrm{R}=0.438, p<0.01)$. This is consistently found across all five neighbourhood types, with correlation coefficients ranging from 0.379 to 0.438 (see Table 8). Levels of happiness, quality of life and environmental condition satisfaction, all subjective measures, are found to vary across the five neighbourhood types: with residents in economic and comfortable housing, suburban public housing and urban village groups enjoying higher levels of subjective well-being than those in new village and small property housing groups.

When examining the objective measures, significant differences in the composition of socio-economic groups in the five neighbourhood types are found. The large majority of residents $(72 \%)$ in urban villages are found to belong to the Urban Adversity group, whereas over half of those living in the economic and comfortable housing group are from the Suburban Comfort group (see Table 2). The criterion-based environmental assessment shows that neighbourhoods in the urban village and small property housing groups have much lower scores than the suburban public housing, economic and comfortable housing and new village groups (see Table 5).

Given that the value of CWB variables varies in different neighbourhood types, this section first examines whether the relationships between different CWB components as set out in the hypotheses exist and then whether they vary among the five suburban neighbourhood types.

\section{H1: Subjective Personal Well-Being Is Related to Socio-Economic Attributes (Reject)}

Subjective personal well-being, in terms of happiness and quality of life, is not found to be statistically related to residents' socio-economic attributes (see Table 6). The values of happiness $($ mean $=3.76)$ and quality of life $($ mean $=3.51)$ are very similar across the three socio-economic groups of Urban Adversity, Twilight Community and Suburban Comfort, though the scores for happiness are higher than for quality of life. In spite of the different socio-economic characteristics of the three groups, arguably with very different levels of objective well-being or personal resources, they all have similar subjective assessments of their personal well-being. After controlling for neighbourhood types, happiness is found to 
Table 5 Statistical relationship between CWB by neighbourhood type

\begin{tabular}{|c|c|c|c|c|c|c|}
\hline \multicolumn{2}{|c|}{$\begin{array}{l}\text { Variables } \\
\text { (Kruskal-Wallis test: } \\
* * p<0.01 ; * p<0.05 \text { ) }\end{array}$} & \multirow{2}{*}{$\begin{array}{l}\begin{array}{l}\text { Economic \& } \\
\text { comfortable } \\
\text { housing }\end{array} \\
3.80\end{array}$} & \multirow{2}{*}{$\begin{array}{l}\text { Suburban public } \\
\text { housing } \\
3.81\end{array}$} & \multirow{2}{*}{$\begin{array}{l}\text { New } \\
\text { village }\end{array}$} & \multirow{2}{*}{$\begin{array}{l}\begin{array}{l}\text { Small } \\
\text { property } \\
\text { housing }\end{array} \\
3.64\end{array}$} & \multirow{2}{*}{$\begin{array}{l}\begin{array}{l}\text { Urban } \\
\text { village }\end{array} \\
3.79\end{array}$} \\
\hline Subjective personal & Happiness $* *$ & & & & & \\
\hline well-being & Quality of life ** & 3.59 & 3.56 & 3.39 & 3.40 & 3.57 \\
\hline $\begin{array}{l}\text { Socio-economic } \\
\text { groups } * *\end{array}$ & $\begin{array}{l}\text { Urban Adversity } \\
(\%)\end{array}$ & 15.50 & 23.20 & 20.10 & 18.20 & 72.20 \\
\hline \multirow[t]{2}{*}{ (Chi-square test) } & $\begin{array}{l}\text { Twilight } \\
\text { Community } \\
(\%)\end{array}$ & 32.10 & 38.10 & 47.70 & 47.80 & 13.50 \\
\hline & $\begin{array}{l}\text { Suburban Comfort } \\
\quad(\%)\end{array}$ & 52.40 & 38.70 & 32.20 & 34.00 & 14.30 \\
\hline \multicolumn{2}{|c|}{$\begin{array}{l}\text { Index of overall environmental condition } \\
\text { satisfaction } * *\end{array}$} & 48.03 & 47.59 & 44.01 & 44.94 & 47.89 \\
\hline \multicolumn{2}{|c|}{$\begin{array}{l}\text { Index of overall neighbourhood } \\
\text { environmental assessment } * *\end{array}$} & 0.47 & 1.63 & 0.26 & -0.53 & -2.09 \\
\hline \multicolumn{2}{|l|}{ Total number } & 464 & 362 & 369 & 247 & 370 \\
\hline
\end{tabular}

be related to socio-economic group only in new village housing, with the Urban Adversity group the least happy.

\section{H2: Satisfaction with Neighbourhood Environmental Conditions Is Related to Socio-Economic Attributes (Accept)}

Different satisfaction levels regarding the neighbourhood environment, measured by an overall index, are found to be statistically significant among the three socio-economic groups. It is interesting to note that residents in both the Urban Adversity and Suburban Comfort groups have above average satisfaction levels, but the Twilight Community group is found to have least satisfaction (see Table 6). The Twilight group also has the lowest satisfaction level across all three sub-indices of environmental conditions (ES1ES3 in Table 6); whereas the Urban Adversity group has above average satisfaction levels. The Suburban Comfort group has above average satisfaction levels for immediate and wider environmental conditions. When examining the hypothesis by neighbourhood type, variations in satisfaction level can be found in economic and comfort housing, suburban public housing and small property housing types. Within these neighbourhood types, the Urban Adversity group has a higher than average level of satisfaction with overall environmental conditions, whereas the opposite is true for the Twilight Community group. The Suburban Comfort group has a similar or above average level of satisfaction in these neighbourhood types.

\section{H3: Subjective Personal Well-Being Is Related to Satisfaction with Neighbourhood Environmental Conditions (Accept)}

Residents' subjective personal well-being is found to be mildly correlated to their satisfaction level regarding overall neighbourhood environmental conditions. 
Table 6 Statistical relationship between CWB and socio-economic group

\begin{tabular}{|c|c|c|c|c|}
\hline $\begin{array}{l}\text { Variables } \\
\text { (Kruskal-Wallis test: } * * p<0.01 ; * p<0.05 \text { ) }\end{array}$ & $\begin{array}{l}\text { Urban } \\
\text { Adversity }\end{array}$ & $\begin{array}{l}\text { Twilight } \\
\text { Community }\end{array}$ & $\begin{array}{l}\text { Suburban } \\
\text { Comfort }\end{array}$ & All \\
\hline Happiness & 3.72 & 3.77 & 3.78 & 3.76 \\
\hline Economic and comfortable housing & 3.75 & 3.8 & 3.82 & 3.80 \\
\hline Suburban public housing & 3.68 & 3.88 & 3.82 & 3.81 \\
\hline New village* & 3.53 & 3.76 & 3.70 & 3.69 \\
\hline Small property housing & 3.62 & 3.59 & 3.73 & 3.64 \\
\hline Urban village & 3.80 & 3.82 & 3.72 & 3.79 \\
\hline Quality of life & 3.52 & 3.49 & 3.53 & 3.51 \\
\hline Economic and comfortable housing & 3.57 & 3.64 & 3.56 & 3.59 \\
\hline Suburban public housing & 3.54 & 3.59 & 3.54 & 3.56 \\
\hline New village & 3.34 & 3.37 & 3.46 & 3.39 \\
\hline Small property housing & 3.48 & 3.34 & 3.44 & 3.40 \\
\hline Urban village & 3.55 & 3.54 & 3.72 & 3.57 \\
\hline Index of overall environmental condition satisfaction** & 47.83 & 45.09 & 47.32 & 46.74 \\
\hline ES1 with wider neighbourhood environment $* *$ & 45.60 & 42.81 & 45.18 & 44.49 \\
\hline ES2 waste management $* *$ & 54.11 & 50.11 & 51.17 & 51.69 \\
\hline ES3 with immediate neighbourhood environment $* *$ & 51.55 & 49.44 & 53.53 & 51.51 \\
\hline Index of overall environmental condition satisfaction** & 47.83 & 45.09 & 47.32 & 46.74 \\
\hline Economic and comfortable housing $* *$ & 50.77 & 46.57 & 48.00 & 48.03 \\
\hline Suburban public housing* & 48.23 & 45.83 & 48.91 & 47.59 \\
\hline New village & 43.76 & 43.96 & 44.21 & 44.01 \\
\hline Small property housing* & 46.12 & 43.56 & 46.25 & 44.94 \\
\hline Urban village & 48.10 & 46.81 & 47.62 & 47.89 \\
\hline Total number & 631 & 542 & 639 & 1812 \\
\hline
\end{tabular}

However, the strength of the relationship is greater with their cognitive well-being of quality of life $(\mathrm{R}=0.406, p<0.01)$, but weaker with their affective happiness level $(\mathrm{R}=0.266, p<0.01)$. When breaking the environmental conditions into different components, via the sub-indices, similar patterns of low levels of correlation are found (see Table 7). Likewise, the relationships are examined across all five neighbourhood types and similar results are found (see Table 8). The correlation between quality of life and environmental satisfaction is found to be stronger in suburban public housing, new village, and small property neighbourhoods (with $\mathrm{R}>0.43, p<0.01$ ), whereas the relationship is weaker in urban villages $(\mathrm{R}=0.372, p<0.01)$ and weakest in economic and comfortable housing $(\mathrm{R}=0.278, p<0.01)$. The correlation between happiness and environmental satisfaction is similar for new village and small property neighbourhoods $(\mathrm{R}>0.31, p<0.01)$, followed by suburban public housing and economic and comfortable housing ( $\mathrm{R}>0.23, p<0.01)$, and finally, is weakest in urban villages $(\mathrm{R}=0.164, p<0.01)$. 


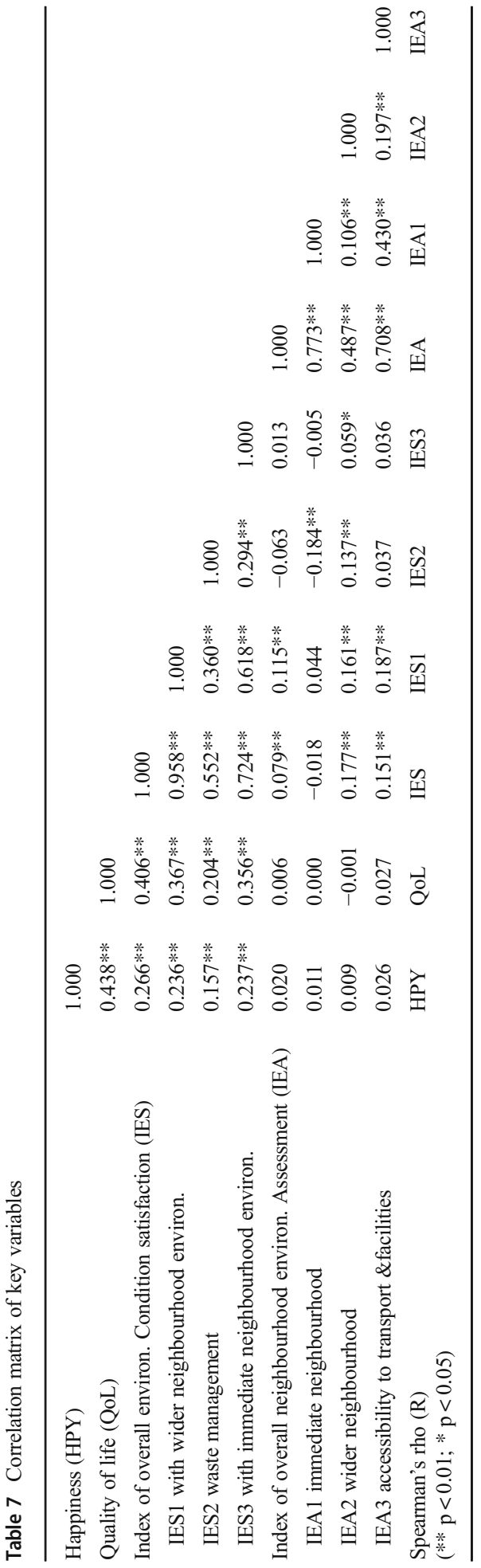


Table 8 Correlation matrix of key variables by neighbourhood type

\begin{tabular}{|c|c|c|c|c|}
\hline $\begin{array}{l}\text { Neighbourhood type } \\
\text { Spearman's rho (R) }(* * \mathrm{p}<0.01 ; * \mathrm{p}<0.05)\end{array}$ & & Happiness & $\begin{array}{l}\text { Quality } \\
\text { of life } \\
\text { (QoL) }\end{array}$ & IES \\
\hline \multirow[t]{3}{*}{ Economic and comfortable housing } & QoL & $0.478 * *$ & 1.000 & \\
\hline & IES & $0.233 * *$ & $0.278^{* *}$ & 1.000 \\
\hline & IEA & 0.029 & 0.019 & $-0.185^{* *}$ \\
\hline \multirow[t]{3}{*}{ Suburban public housing } & QoL & $0.417 * *$ & 1.000 & \\
\hline & IES & $0.258 * *$ & $0.430 * *$ & 1.000 \\
\hline & IEA & 0.042 & 0.065 & $0.410^{* *}$ \\
\hline \multirow[t]{3}{*}{ New village } & QoL & $0.451 * *$ & 1.000 & \\
\hline & IES & $0.343 * *$ & $0.464 * *$ & 1.000 \\
\hline & IEA & -0.059 & -0.086 & 0.021 \\
\hline \multirow[t]{3}{*}{ Small property housing } & QoL & $0.421 * *$ & 1.000 & \\
\hline & IES & $0.317 * *$ & $0.451 * *$ & 1.000 \\
\hline & IEA & -0.043 & -0.11 & $-0.237 * *$ \\
\hline \multirow[t]{3}{*}{ Urban village } & QoL & $0.379 * *$ & 1.000 & \\
\hline & IES & $0.164 * *$ & $0.372 * *$ & 1.000 \\
\hline & IEA & -0.012 & -0.082 & $0.120 *$ \\
\hline
\end{tabular}

Index of overall environmental condition satisfaction (IES); index of overall neighbourhood environmental assessment (IEA)

\section{H4: Subjective Personal Well-Being Is Related to Neighbourhood Environmental Assessment (Reject)}

There is no significant correlation between the neighbourhood environmental assessment index and subjective personal well-being, in terms of perceived happiness and quality of life (see Table 7). When breaking down the assessment into sub-indices, no significant relationships are found. Again, no significant relationships are found when testing the hypothesis across the five neighbourhood types (see Table 8).

\section{H5: Satisfaction with Neighbourhood Environmental Conditions Is Related to Neighbourhood Environmental Assessment (Accept)}

The correlation coefficient between subjective satisfaction with environmental conditions and objective criterion-based assessment, as measured by two overall indices, is surprisingly low $(\mathrm{R}=0.079, p<0.01)$ but nevertheless statistically significant (see Table 7). When testing the relationship among the sub-indices, only satisfaction with the wider neighbourhood (ES3 and EA2) is weakly correlated $(\mathrm{R}=0.161, p<0.01)$. However, the relationship is far more complex once analysis is made across different neighbourhood types (see Table 8). The relationship between subjective and objective measures of environmental quality is moderately correlated for the suburban public housing group $(\mathrm{R}=0.41, p<$ $0.01)$ and weakly correlated for urban villages $(\mathrm{R}=0.12, p<0.01)$. However, a 
negative relationship is found in small property housing $(\mathrm{R}=-0.237, p<0.01)$ and economic and comfortable housing $(\mathrm{R}=-0.185, p<0.01)$ types.

\section{Summary of Hypothesis Testing Results}

The testing of the five hypotheses has rejected $\mathrm{H} 1$ and $\mathrm{H} 4$, which means that subjective personal well-being (both in terms of happiness and quality of life) is not found to be related to the objective measure of personal conditions (in terms of socio-economic group) and residential condition (in terms of environmental assessment). Statistical testing has, however, accepted H2, H3 and H5. While personal well-being and socioeconomic group are not related, they are both related to neighbourhood environmental satisfaction level which is positively correlated to the environmental assessment results. All variables of CWB, both subjective and objectives ones, are related to different neighbourhood types. These findings of the hypothesis testing are further confirmed when controlled by neighbourhood type.

\section{CWB and Sustainable Urbanisation: Research Findings and Policy Implications}

Based on the above findings, this section discusses the relationship between CWB and sustainable urbanisation and compares the findings with other studies. It then draws planning policy implications for achieving a new type of urbanisation in China.

\section{The Chinese Cultural Context}

The values of happiness (mean 3.76) and quality of life (mean 3.51) in this study confirm previous personal well-being research that Chinese respondents are more likely to choose moderate scores and express contentment with their lives. The Chinese conception of happiness is more about maintaining harmonious relationships with others and being at ease with life, which often means making compromises and adjusting expectations to make way for more content lives ( $\mathrm{Lu}$ and Shih 1997). Therefore, lower individualism is linked to a happier life (Steel et al. 2018). In addition, socialist values do not emphasise individualism which to some extent may explain the relative satisfaction of respondents. Others also argue that Chinese respondents do not always differentiate happiness from life satisfaction when making references to wellbeing (Lau et al. 2005). However, happiness and life satisfaction as distinct but statistically correlated concepts were established in research on European countries, with life satisfaction being more specific and cognitively oriented and happiness as a more diffuse sentiment (Gundelach and Kreiner 2004). Our findings lent support to the European findings, as happiness and quality of life are moderately correlated, which suggests that they are measuring different dimensions of personal well-being.

\section{Paradoxical Relationship between Subjective and Objective CWB}

The three socio-economic groups, arguably with very different levels of personal resources, all have similar subjective assessments of their well-being in terms of 
happiness, quality of life and environmental satisfaction. This lends support to the paradoxical findings between objective and subjective personal well-being in previous studies of China (see Davy and Rato 2012). The discord between subjective and objective well-being among residents is particularly stark when examining differences across the five neighbourhood types, especially as residents in the urban village type exhibit a high level of contentment and satisfaction with their well-being, despite the fact that their objective socio-economic well-being and living environmental conditions are the least desirable (given that $72 \%$ residents in urban villages belong to the Urban Adversity group). This confirms socio-temporal arguments made in previous studies that the relative improvement in migrant workers' lives in Beijing, Shanghai and Guangzhou has fostered contentment ( $\mathrm{Li}$ and $\mathrm{Wu}$ 2013). Another explanation comes from the critique of the utility approach towards poverty alleviation that people can adapt and be conditioned to bear hardship and deprivation (Sen 2012). In spite of the adverse standard of living environment, once migrant workers get used to such a situation, their subjective satisfaction levels can be moderately positive. The paradoxical relationship between subjective and objective CWB also highlights the importance of the socio-cultural aspects of well-being beyond material improvement. Both objective and subjective measures contribute to our understanding of different aspects of well-being and should not be used exclusively (Golden 2017).

\section{Less Satisfied Twilight Community: Role of Socio-Temporal Comparison Effect}

The Twilight group consistently has the lowest satisfaction levels (below average) across the overall and all three sub-indices of environmental conditions. When controlled by neighbourhood types, variations in satisfaction level can be found in economic and comfort housing, suburban public housing and small property housing types; and the Twilight Community group has a below average level of satisfaction, lower than the Urban Adversity and Suburban Comfort groups. The findings pose a very interesting and important question: Why do the older and more established communities have lower satisfaction levels than their counterparts living in even more adversarial conditions? This differs from the findings of Davey et al. (2009) that middle-aged and elderly respondents in a farming community tend to be more content with their lives. However, such contentment is probably related to socio-temporal comparison at the time, as evident in the Urban Adversity group's general contentment in this study. To the Twilight group, the effect of temporal comparison with the past may have diminished, but the effect of social comparison with other more affluent groups' living environment in the capital city may gradually increase.

\section{Environmental Satisfaction, Well-Being and Neighbourhood Types}

Levels of happiness, quality of life and environmental condition satisfaction are found to vary across the five suburban neighbourhood types in Beijing: residents in economic and comfortable housing, suburban public housing and urban village groups enjoy higher levels of subjective well-being than those in the new village and small property housing groups. The findings indeed echo the recent study by Dang et al. (2017) on central Beijing districts where neighbourhood type (by housing classification) was significantly related to subjective well-being, with residents in commercial housing 
neighbourhoods and urban villages reporting higher levels of subjective well-being. It is important to note the very weak relationship between subjective satisfaction with, and the objective assessment of, environmental conditions, though statistically significant. While residents' subjective personal well-being (both in terms of happiness and quality of life) is found to be mildly related to their level of satisfaction with environmental conditions, there is no significant correlation with objective environmental assessment. Our findings in suburban Beijing match with those of Ma et al. (2018) regarding Beijing's urban core, where subjective neighbourhood evaluation has a greater influence on life satisfaction than the objective residential environment.

\section{Policy Implications for New Type of Urbanisation}

The criterion-based environmental assessment shows that neighbourhoods in the urban village and small property housing types, both with ambiguous land development rights, have much lower scores than the other three types. Due to the lack of resources from government and the private developer, development in these two neighbourhood types is spontaneous and of poor quality. As discussed above, only a very weak relationship exists between the subjective satisfaction with and the objective assessment of environmental conditions and the objective environmental assessment does not bear any significant relationship to residents' subjective well-being. This suggests that more factors must be taken into account for a more grounded understanding of well-being: while material improvement matters, social and human-based factors also make a difference. Given the high level of contentment across different CWB variables, it is very difficult to argue for more robust policy measures to improve the residential environment of these rapidly developed suburban neighbourhoods that often do not have adequate infrastructural support and public amenities. Indeed, these moderate responses from residents will simply allow developers and government to focus on quantity rather than quality of development and is likely to induce further urban expansion and sprawl, pushing the frontier of the peri-urban area outwards. This is precisely the development trend that the state tries to alter with the introduction of the NUP, by emphasising the importance of ecological civilisation and a human-centred urbanisation approach. There is, therefore, a need to fostering a cultural shift among planners and local government officials to engage residents in the planning process and to establish their desirable thresholds of different aspects of CWB. Since residents' desires and needs of well-being vary over time and under different socio-spatial contexts, new type of urbanisation should not just focus on new residential development, but also on urban renewal and regeneration of existing residential communities.

\section{Conclusion}

While dissonance between subjective and objective personal well-being has been widely reported in previous studies in China, the relationship between personal well-being and environmental conditions has been less well-researched. This study has bridged this research gap by taking both personal attributes and neighbourhood environmental factors into account to examine different components of CWB in the suburbs of the outer metropolitan area of Beijing. The findings highlight variations across different 
neighbourhood types over residents' levels of happiness, quality of life and satisfaction with environmental conditions. Neighbourhood type is found to be particularly revealing when examining the relationship between the environmental satisfaction level and personal well-being. This line of inquiry has only recently started in China and could be further developed in future CWB research. From a spatial planning perspective, the improvement of CWB requires strategic policy thinking and effective implementation at different spatial scales. The neighbourhood, as the core geographic and social unit for planning, is critical to foster CWB by linking individuals, their nested communities and other larger spatial scales to deliver a coherent policy framework. While the NUP is a top-down policy introduced by the state, to achieve a 'moderately well-off and comfortable society' will require bottom-up participation and engagement of the community to address their desires over time and over different aspects of CWB.

Another important finding is the paradoxical relationship between subjective and objective CWB, especially for the Urban Adversity group who are mainly concentrated in urban villages, which is probably related to their more favourable comparison with their previous experiences. However, the lowest contentment level of the Twilight Community group suggests that the context of comparison is changing as time goes by. Since subjective well-being is in a state of flux, this will require longitudinal research with cohort or panel studies to capture these changes in order to develop a more robust evidence-base for community planning and development. The findings in the paper help to provoke debates on the measurements and policy goals of CWB, especially for other communities beyond China which are also undergoing a rapid urbanisation process. The measurement and normative assessment of CWB remain challenging and controversial; concerted efforts from both academia and the policy community will be needed to push the agenda forward.

Acknowledgements The project is funded by the UK Economic and Social Research Council (Grant Number ES/N010698/1). The authors declare that they have no conflict of interest.

Open Access This article is distributed under the terms of the Creative Commons Attribution 4.0 International License (http://creativecommons.org/licenses/by/4.0/), which permits unrestricted use, distribution, and reproduction in any medium, provided you give appropriate credit to the original author(s) and the source, provide a link to the Creative Commons license, and indicate if changes were made.

\section{References}

Allen, A. (2003). Environmental planning and management of the peri-urban interface: Perspectives on an emerging field. Environment and Urbanization, 15(1), 135-148.

AtKisson, A. (2006). Sustainability is dead - Long live sustainability. In M. Keiner (Ed.), The future of sustainability (pp. 231-243). Dordrecht: Springer.

Beauregard, R. A. (2006). When America became suburban. Minneapolis: University of Minnesota Press.

Bettencourt, L., \& West, G. (2010). A unified theory of urban living. Nature, 467(7318), 912.

Chang, I. C., Leitner, H., \& Sheppard, E. (2016). A green leap forward? Eco-state restructuring and the Tianjin-Binhai eco-city model. Regional Studies, 50, 929-943.

Chen, Z., \& Davey, G. (2008). Happiness and subjective wellbeing in China. Journal of Happiness Studies, 9(4), 589-600.

Cheng, H., Liu, Y., He, S., \& Shaw, D. (2017). From development zones to edge urban areas in China: A case study of Nansha, Guangzhou City. Cities, 71, 110-122. 
Cummins, R. A. (2018). Measuring and interpreting subjective wellbeing in different cultural contexts: A review and way forward. Cambridge: Cambridge University Press.

Cuthill, M. (2002). Coolangatta: A portrait of community well-being. Urban Policy and Research, 20(2), 187-203.

Dang, Y., Dong, G., Chen, Y., Jones, K., \& Zhang, W. (2017). Residential environment and subjective wellbeing in Beijing: A fine-grained spatial scale analysis using a bivariate response binomial multilevel model. Environment and Planning B: Urban Analytics and City Science, 0(0), 1-20.

Davey, G., Chen, Z., \& Lau, A. (2009). Peace in a thatched hut-that is happiness: Subjective wellbeing among peasants in rural China. Journal of Happiness Studies, 10(2), 239-252.

Davy, G., \& Rato, R. (2012). Subjective well-being in China: A review. Journal of Happiness Studies, 13, 333-346.

Diener, E. (2006). Guidelines for national indicators of subjective well-being and ill-being. Journal of Happiness Studies, 7, 397-404.

Diener, E., Suh, E. M., Lucas, R. E., \& Smith, H. L. (1999). Subjective well-being: Three decades of progress. Psychological Bulletin, 125, 276-302.

Dong, H., \& Qin, B. (2017). Exploring the link between neighbourhood environment and mental wellbeing: A case study in Beijing, China. Landscape and Urban Planning, 164, 71-80.

Dunstan, F., Weaver, N., Araya, R., Bell, T., Lannon, S., Lewis, G., Patterson, J., Thomas, H., Jones, P., \& Palmer, S. (2005). An observation tool to assist with the assessment of urban residential environments. Journal of Environmental Psychology, 25(3), 293-305.

Fleury-Bahi, G., Marcouyeux, A., Préau, M., \& Annabi-Attia, T. (2013). Development and validation of an environmental quality of life scale: Study of a French sample. Social Indicators Research, 113(3), 903-913.

Foo, K., Martin, D., Polsky, C., Wool, C., \& Ziemer, M. (2015). Social well-being and environmental governance in urban neighbourhoods in Boston, MA. The Geographical Journal, 181(2), 138-146.

Francesch-Huidobro, M. (2016). Climate change and energy policies in Shanghai: A multilevel governance perspective. Applied Energy, 164, 45-56.

Galster, G. (2001). On the nature of neighbourhood. Urban Studies, 38(12), 2111-2124.

Golden, L. (2017). A Happiness and Objective Well-Being Index (HOW-IS-IL) for Living and Working in the State of Illinois, 2016-17. https://doi.org/10.2139/ssrn.3044508

Gundelach, P., \& Kreiner, S. (2004). Happiness and life satisfaction in advanced European countries. CrossCultural Research, 38(4), 359-386.

Hagenaars, J. A., \& McCutcheon, A. L. (Eds.). (2002). Applied latent class analysis. Cambridge: Cambridge University Press.

Hamiduddin, I. (2015). Social sustainability, residential design and demographic balance: Neighbourhood planning strategies in Freiburg, Germany. Town Planning Review, 86(1), $29-52$.

Harris, P., Brunsdon, C., \& Charlton, M. (2011). Geographically weighted principal components analysis. International Journal of Geographical Information Science, 25(10), 1717-1736.

Helliwell, J., Layard, R., \& Sachs, J. (2016). World Happiness Report 2016, Update (Vol. I). New York: Sustainable Development Solutions Network. http://worldhappiness.report/ed/2016/. Accessed 11 Feb 2019.

Holden, M., Roseland, M., Ferguson, K., \& Perl, A. (2008). Seeking urban sustainability on the world stage. Habitat International, 32(3), 305-317.

Hothi, M., Bacon, N., Brophy, M., \& Mulgan, G. (2008). Neighbourliness + empowerment = wellbeing: Is there a formula for happy communities? London: The Young Foundation. https://youngfoundation. org/wp-content/uploads/2015/04/N_E_W_web.pdf. Accessed 11 Feb 2019.

Huang, I., \& Xing, Z. (2005). An initial research on the wellbeing index applied to citizens in China. Chinese Journal of Behavioral Medical Science, 114(5), $464-465$ (In Chinese).

Jolliffe, I. (2011). Principal component analysis. In International encyclopedia of statistical science (pp. 1094 1096). Berlin, Heidelberg: Springer.

Kee, Y. (2017). Multi-dimensional model of community well-being from a public service delivery perspective. In R. Phillips \& C. Wong (Eds.), Handbook of community well-being research (pp. 69-84). Dordrecht: Springer.

Lau, A., Cummins, R., \& McPherson, W. (2005). An investigation into the cross-cultural equivalence of the personal wellbeing index. Social Indicators Research, 72, 403-430.

Lee, S. J., Kim, Y., \& Phillips, R. (2015). Exploring the intersection of community well-being and community development. In S. J. Lee, Y. Kim, \& R. Phillips (Eds.), Community well-being and community development (pp. 1-7). New York: Springer.

Li, Z., \& Wu, F. (2013). Residential satisfaction in China's informal settlements: A case study of Beijing, Shanghai, and Guangzhou. Journal of Urban Geography, 34(7), 923-949. 
Liu, Z., Liang, S., Geng, Y., Xue, B., Xi, F., Pan, Y., Zhang, T., \& Fujita, T. (2012). Features, trajectories and driving forces for energy-related GHG emissions from Chinese mega cites: The case of Beijing, Tianjin, Shanghai and Chongqing. Energy, 37, 245-254.

Liu, Y., Dijst, M., \& Geertman, S. (2017). The subjective well-being of older adults in Shanghai: The role of residential environment and individual resources. Urban Studies, 54(7), 1692-1714.

Liu, L., Silva, E.A. and Long, Y. (2018) Block-level changes in the socio-spatial landscape in Beijing: Trends and processes. Urban Studies, online publication (March 2018). https://journals.sagepub. com/doi/pdf/10.1177/0042098018757617. Accessed 11 Feb 2019.

Lu, L., \& Shih, J. B. (1997). Sources of happiness: A qualitative approach. The Journal of Social Psychology, 137(2), 181-187.

Ma, J., Dong, G., Chen, Y., \& Zhang, W. (2018). Does satisfactory neighbourhood environment lead to a satisfying life? An investigation of the association between neighbourhood environment and life satisfaction in Beijing. Cities, 74, 229-239.

Miles, I. (1985). Social indicators for human development. London: Frances Pinter.

Nieboer, A., Lindenber, S., Boomsma, A., \& Bruggen, A. C. V. (2005). Dimensions of well-being and their measurement: The Spf-Il scale. Social Indicators Research, 73, 313-353.

Nielsen, I., Smyth, R., \& Zhai, Q. (2010). Subjective wellbeing of China's off-farm migrants. Journal of Happiness Studies, 11, 315-333.

O’Neill, B. C., Ren, X., Jiang, L., \& Dalton, M. (2012). The effect of urbanization on energy use in India and China in the iPETS model. Energy Economics, 34, S339-S345.

Phillips, R., \& Wong, C. (2017). Introduction. In R. Phillips \& C. Wong (Eds.), Handbook of community wellbeing research (pp. xxix-xxxviii). Dordrecht: Springer.

Rauws, W. S., \& de Roo, G. (2011). Exploring transitions in the peri-urban area. Planning Theory and Practice, 12(2), 269-284.

Rohe, W. M. (2009). From local to global: One hundred years of neighborhood planning. Journal of the American Planning Association, 75(2), 209-230.

Roy, M. (2009). Planning for sustainable urbanisation in fast growing cities: Mitigation and adaptation issues addressed in Dhaka, Bangladesh. Habitat International, 33, 276-286.

Ryan, R. M., \& Deci, E. L. (2001). On happiness and human potentials: A review of research on hedonic and eudaimonic well-being. Annual Review of Psychology, 52(1), 141-166.

Savage, V.R., \& Feng, L.Q. (2018). 'Ecological civilisation': China's ideological counter-view? RSIS Commentary, Nanyang Technology University, Singapore, No. 122, $19^{\text {th }}$ July. https://dr.ntu.edu. sg/handle/10220/45169. Accessed 11 Feb 2019.

Sawiciki, D., \& Flynn, P. (1996). Neighbourhood indicators: A review of the literature and an assessment of conceptual and methodological issues. Journal of the American Planning Association, 62(2), 165-183.

Schwanen, T., \& Atkinson, S. (2015). Geographies of wellbeing: An introduction. The Geographical Journal, 181(2), 98-101.

Sen, A. (2012) Development as capability expansion. In J. DeFilippis and S. Saegert (eds) The community development reader (pp. 319-327). New York: Routledge.

Smyth, R., Nielsen, I., \& Zhai, Q. (2010). Personal wellbeing in urban China. Social Indicators Research, 95 , 231-251.

State Council. (2014). National new Urbanisation Plan (2014-2020). Beijing: State Council.

Steel, P., Taras, V., Uggerslev, K., \& Bosco, F. (2018). The happy culture: A theoretical, meta-analytic, and empirical review of the relationship between culture and wealth and subjective well-being. Personality and Social Psychology Review, 22(2), 128-169.

Sun, L., Li, C., Gwilliam, J., \& Jones, P. (2011). Challenges to sustainable peri-urban settlement development in China: An analysis by empirical evidence in Tianjin. In C. A. Brebbia (Ed.), Sustainability today (pp. 3-14). Southampton: WIT Press.

Sung, H., \& Phillips, R. (2016). Conceptualizing a community well-being and theory construct. In S. J. Lee, Y. Kim, \& R. Phillips (Eds.), Social factors and community well-being (pp. 1-12). Dordrecht: Springer.

Talen, E., \& Shah, S. (2007). Neighborhood evaluation using GIS: An exploratory study. Environment and Behavior, 39(5), 583-615.

UNDP [United Nations Development Programme]. (2013). Sustainable and liveable cities: Toward ecological civilization, China National Human Development Report. Beijing: China Translation \& Publishing Corporation.

UN-Habitat [United Nations Human Settlements Programme] (2012). State of the world's cities 2012/13: Prosperity of cities. Nairobi, Kenya: UN-Habitat.

UN-Habitat [United Nations Human Settlements Programme] (2016). Habitat III New Urban Agenda: Draft outcome document for adoption in Quito, October 2016. Nairobi: UN-Habitat. 
Van Kamp, I., Leidelmeijer, K., Marsman, G., \& De Hollander, A. (2003). Urban environmental quality and human well-being: Towards a conceptual framework and demarcation of concepts; a literature study. Landscape and Urban Planning, 65(1-2), 5-18.

Wang, D., \& Chai, Y. (2009). The jobs-housing relationship and commuting in Beijing, China: The legacy of Danwei. Journal of Transport Geography, 17, 30-38.

Watson, G. B. (2016). Designing sustainable cities in the developing world. London: Routledge.

Wiseman, J., \& Brasher, K. (2008). Community wellbeing in an unwell world: Trends, challenges, and possibilities. Journal of Public Health Policy, 29(3), 353-366.

Wong, C. (2015). A framework for 'City prosperity index': Linking indicators, analysis and policy. Habitat International, 45, 3-9.

Wong, C., Qiao, M., \& Zheng, W. (2018). 'Dispersing, regulating and upgrading': Urban villages in suburban Beijing. Town Planning Review, 89(6), 597-621. https://doi.org/10.3828/tpr.2018.41.

Wong, C., Qiao, M., Zheng, W., Kingston, R., Wang, L., \& Taheri, S. (2018) Methodology of Community Survey in Beijing Metropolitan Area: spatial typology, sampling methods and questionnaire design. Working Paper. Manchester Urban Institute (SPA-Lab).

Wu, F. (2016). China's emergent city-region governance: A new form of state spatial selectivity through stateorchestrated rescaling. International Journal of Urban and Regional Research, 40, 1134-1151.

Wu, F., Zhang, F., \& Webster, C. (2013). Informality and the development and demolition of urban villages in the Chinese peri-urban area. Urban Studies, 50, 1919-1934.

Zhao, P. (2012). Urban-rural transition in China's metropolises: New trends in peri-urbanisation in Beijing. International Development Planning Review, 34(3), 269-294.

Zhao, P., Lu, B., \& de Roo, G. (2011). The impact of urban growth on commuting patterns in a restructuring city: Evidence from Beijing. Papers in Regional Science, 90(4), 735-754.

Publisher's Note Springer Nature remains neutral with regard to jurisdictional claims in published maps and institutional affiliations. 